\title{
SOCIEDADES RELIGIOSAS Y ORGANIZACIONES PRIVADAS DE BENEFICENCIA EN LA FRONTERA NORTE (TIJUANA): UN PRIMER ACERCAMIENTO
}

\author{
Por \\ Víctor Clark Alfaro*
}

\section{RESUMEN}

A partir de la década de los setenta se da un crecimiento importante de organizaciones religiosas en América Latina y del que la frontera norte no ha sido ajeno.

El propósito de esta investigación es dar una visión aproximada de la presencia cada vez más numerosa de sociedades religiosas y organizaciones privadas de beneficencia y su impacto social en distintos ámbitos de la ciudad de Tijuana con una breve referencia a la zona rural (San Quintín). La información que se ofrece fue recopilada antes de la reforma al artículo 130 de la Constitución de los Estados Unidos Mexicanos.

\section{ABSTRACT}

Since the decade of the 70's an important growth of religious organizations occurs in Latin America, and the Mexican northern border has not been excluded from it.

The purpose of this investigation is to offer a rough vision of the presence - more numerous every day - of private and charity religious organizations and their social impact on different areas of the city of Tijuana, with a short account of the rural area (San Quintin). It should be made clear that this article was written before the reforms to the 130th article of the Constitution of the United States of Mexico.

\section{INTRODUCCIÓN ${ }^{1}$}

Uno de los fenómenos sociales masivos más importantes del siglo Xx en México, es sin duda el crecimiento de las sociedades religiosas no católicas provenientes de Estados Unidos. El tema ha llamado la atención del Estado y principalmente de la iglesia católica.

* Estudió maestría en antropología social en la Universidad Iberoamericana. Realizó estudios de doctorado en sociología en la Universidad de California en San Diego. Actualmente es director del Centro Binacional de Derechos Humanos A. C. en Tijuana, B.C.

Deseo agradecer al profesor Michael Kearney sus comentarios al primer borrador de este texto; lo mismo a José Valderrey la revisión al primer texto preliminar del trabajo, sus valiosas observaciones y sus estímulos para continuar analizando el tema de las sociedades religiosas en la frontera norte. 
El propósito de este estudio es dar una aproximación general sobre varios temas relacionados con la presencia de sociedades religiosas no católicas (SR), y que a su vez sirva de motivación intelectual a otros investigadores para profundizar en los tópicos tratados.

Es intención del autor plantear, a manera de colección, varios temas que quizá inicialmente no tengan relación entre sí, excepto el tema religioso o del asistencialismo, con el propósito de dejar en el lector la idea de la diversidad en que el campo religioso se presenta.

Aclaramos que a lo largo del trabajo utilizaremos el término de sociedades religiosas (SR), para referimos a todas las manifestaciones religiosas organizadas: sectas, denominaciones e iglesias. ${ }^{2}$

2 No es pretención de este trabajo entrar en la discusión sobre las diferencias entre secta-culto, denominación-iglesia, por eso decidimos llamarles a estas formas sociedades religiosas, sin embargo, creímos pertinente establecer de manera breve algunas de sus características.

El concepto de secta se ha prestado a confusiones y ha adquirido además, un sentido peyorativo al grado tal que las SR que tienen la categoría sociológica de secta, prefieren llamarse a sí mismas iglesias, pero nunca sectas.

En principio, la secta es la organización religiosa mínima, aunque existen otras formas más elaboradas y complejas, que en orden de su importancia organizativa serian: las denominaciones y las iglesias. Una secta puede o no evolucionar al nivel de denominación o iglesia, tener un proceso inverso o sencillamente desaparecer, como fue el caso de los shakers secta que apareció a fines de 1700 en Inglaterra y se expandió a Estados Unidos; practico el celibato y la separación de los sexos, por lo que en pocos años se extinguió.

Existen diferentes perspectivas para identificar la dicotomia iglesia-secta, desde la tipologia propuesta por el teólogo Ernst Troeltsch, pero introducida en la sociologia por su maestro Max Weber, hasta los planteamientos de Liston Pope (1942:122-124) quien plantea veintiún distinciones entre una iglesia y una secta. De acuerdo con Demerath y Hammond (citados por Ronald L. Johnstone (1975:111-112), Las diferencias entre iglesia y secta pueden analizarse desde dos perspectivas, una por sus características intemas de organización; y otra por las relaciones externas del grupo con su medio ambiente. La distinción sociológica fundamental es la estructura organizativa de la SR. Existe un continuum entre los dos extremos secta-iglesia, cuyas diferencias son el grado de complejidad en su estructura organizativa. De acuerdo con la clasificación de Demerath y Hammond, a la que consideramos ilustrativa aunque se refiere al tipo ideal, se establecen diez distinciones:

1) Una secta se ve a sí misma como el grupo elegido; por ejemplo, como la personificación de los verdaderos creyentes.

2) Las sectas fomentan la espontaneidad de las expresiones religiosas que involucran una extensiva participación del grupo.

3) Las sectas no enfatizan en la organización, se esfuerzan por mantener una máxima participación democrática de sus miembros con una estructura explícita no-burocrática.

4) Una secta es usual y deliberadamente pequeña.

5) Las sectas utilizan seglares como líderes. Frecuentemente los líderes son de medio tiempo y tienen poco, o ningún, entrenamiento teológico formal. El compromiso con los principios declarados por el grupo es visto como más importante que "aprenderse el tibro". El elemento carismático es un rasgo común de los líderes.

6) Una secta enfatiza en la pureza de la doctrina y usualmente demanda un regreso a las enseñanzas originales. Esto involucra una renunciación a las perversiones y aberraciones doctrinales que acusan a las denominaciones religiosas establecidas por haber permitido introducirlas en la verdadera religión. 
El estudio describe y analiza la presencia de SR con particular énfasis en el área de: migración, el medio rural, la educación y colonias populares; tampoco pueden dejarse al margen los grupos norteamericanos de beneficencia, conocidos también como charity groups, y su impacto en colonias populares. En Tijuana, ambos grupos han crecido en los últimos años, significando una mayor competencia en el campo religioso, y fomentando actitudes y relaciones asistencialistas, sobre todo de las organizaciones privadas de beneficencia (OPB).

7) Una secta enfatiza en los principios éticos tradicionales, y se esfuerza para influir en sus miembros en un amplio espectro de conductas.

8) Las sectas tienden a concentrarse en aspectos del mundo por venir (la salvación, liberación, cielo oinfierno) y desprecian los asuntos de este mundo. Incluso su énfasis en la écica se enfoca menos en las relaciones del hombre y más en la relevancia de los asuntos del otro mundo.

9) Una secta gana nuevos miembros primariamente a través de la conversión, es inicialmente una sociedad de adultos, sin embargo, eventualmente deberán voltear su atención a la socialización religiosa de los niños.

10) Una secta atrae desproporcionalmente a miembros de las clases bajas de la sociedad. Implícita en muchas de las características anteriomnente descritas está la principal característica de una secta, la protesta. Usualmente su protesta es en contra de a) formas religiosas tradicionalmente establecidas y grupos que los miembros de la secta sienten que se han alejado de la religión prístina, y b) la sociedad secular circundante, que es vista como encamando toda clase de males. Una secta, refleja un cisma -una ruptura y un rechazo de los patrones establecidos, tanto religiosos como seculares-.

En cuanto a las características de la organización religiosa del tipo iglesia serían:

1) clama universalidad e incluye a todos los miembros de la sociedad dentro de sus rangos; existe una fuerte tendencia de "ciudadanos" a ser equiparados como "miembros":

2) ejercita el monopolio religioso y trata de eliminar la competencia religiosa;

3) es una cercana aliada con el Estado y los poderes seculares; frecuentemente existe un traslape de responsabilidades y de mutuo reforzamiento;

4) está ampliamente organizada como una jerarquía institucional burocrática con una compleja división del trabajo;

5) emplea profesionales, clero de tiempo completo que posee las apropiadas credenciales de educación y ordenación formal;

6) casi por definición gana nuevos miembros a través de la reproducción natural y la socialización de los niños.

Es importante establecer, como lo hace Valderrey (1985:5), el criterio doctrinal para diferenciar a las SR:

a) Por una parte las sociedades religiosas llamadas generalmente protestantes. Es decir, todas aquéllas que tienen a la biblia como único texto normativo. A todas ellas se les considera dentro de a tradición cristiana y su inmensa mayoría arrancan de la Reforma del siglo XVI. (Aquí no incluye a los testigos de Jehová ni a la Iglesia de los Santos de los Ultimos Días - mormones- quienes no están considerados corno evangélicos o protestantes, pues además de la biblia disponen de otros textos normativos).

b) Aquellas sociedades que no pertenecen a la tradición anterior, tienen más bien caracteres sincréticos cuyos componentes predominantes son cristianos y de origen oriental. Más raramente se encuentran elementos indígenas y africanos. $\mathrm{La}$ Conferencia de Puebla los menciona con el nombre de "sincretismos foráneos". 
Este trabajo se basó, fundamentalmente, en la observación participante en Tijuana con 17 sociedades religiosas; así como en las entrevistas abiertas a sus pastores, ministros, ruiseñores, etcétera; lo mismo que en el trabajo de campo en San Quintín y en tres colonias populares de Tijuana con alta presencia de sociedades religiosas y privadas de beneficencia. ${ }^{3}$

Por el carácter fronterizo y su cercanía con California - estado que ocupa el tercer lugar de la unión americana en cuanto a número de cultos y el lugar número 29 por su número de sectas (Stark, 1985:144-193)—, Tijuana no escapa a esta influencia ideológica aculturizante. ${ }^{4}$ Los fronterizos mexicanos se han convertido en el mercado de adeptos potenciales, por ser el país subdesarrollado más cercano a Estados Unidos. En la última década, acompañado a los crecientes procesos de urbanización y migración, ha aparecido en Tijuana una pluralidad de SR con orientaciones muy diversas; para 1988 había 56 denominaciones en Tijuana (Hernández, 1989); en Mexicali, la capital del estado de Baja California, para junio de 1988 existían aproximadamente 320 grupos religiosos, distribuidos en 31 organizaciones y 86 congregaciones independientes; en Ensenada 14 sectas, cultos y denominaciones (Backhoff, 1987); y para el país de acuerdo con la XXXVI Asamblea Plenaria de la Conferencia del Episcopado Mexicano, celebrada en 1985, "no hay una estadística completa" (Excélsior, 19 de abril de 1985); el Mission Handbook anota, para 1973, a 125 organizaciones protestantes norteamericanas en México cuyas primeras iglesias se establecieron entre 1861 y 1870 .

Se estima que en el siglo XX en América Latina un mayor número de católicos se han vuelto protestantes comparado con la conversión que ocurrió en toda Europa durante la Reforma. En 1914 había 100,000 protestantes, para 1960 la cifra superaba ya los 10 millones (Whalen, 1979:17), y para 1980 la proyección era de 16.6 millones (La Jornada, 17 de abril de 1985); sin embargo, para otras fuentes, como la agencia de noticias ecuménica de Brasil, el número de protestantes se habría incrementado de 12 a 30 millones desde 1978 , la mayoría miembros de iglesias evangelistas y

3 Las siguientes son las SR con las que realizamos trabajo de campo: Testigos de Jehová, Adventistas del Séptimo Día, Espiritualistas Trinitarios Marianos, Iglesia de los Santos de los Ultimos Días, Iglesia de la Comunidad Metropolitana, NCM Nichirem Shosho de México, Vudú, Conciencia de Krisna, Asociación Baha'ie de México, Centro Cristiano la Puerta, Centro Amistad Cristiana de Tijuana, Iglesia del Nazareno, Cruzada Evangelística Mundial, Iglesia Pentecostés del Calvario (perteneciente a la Iglesia Pentecostés Cuadrangular que también se visitó).

4 Se estima el número de iglesias y sectas en Estados Unidos en 265 (citado en Whalen, 1979:11). 
pentecostales (Times, 16 de marzo de 1987). Conocer con exactitud el número de SR, e incluso el número de templos que existen en el país, es una tarea difícil. En México se encuentran grupos que pueden estar integrados desde 10 hasta 10,000 miembros o más, muchos de cuyos templos se ocultan en las vecindades de las grandes ciudades.

El crecimiento de las SR en Tijuana ha sido rápido para unos y lento para otros. Por ejemplo, la Asociación Baha'ie de México sólo contaba con alrededor de 15 adeptos para 1984. Otros grupos incrementan con mayor rapidez su membresía debido a exitosas estrategias de reclutamiento. El espectro religioso en Tijuana es amplio, encontramos desde grupos practicantes del vudú, budistas, espiritualistas, krisnas, iglesia para la comunidad homosexual (iglesia de la comunidad metropolitana), hasta una cantidad no determinada de grupos pentecostales, que constituyen la mayoría. Un alto número es el resultado de misiones provenientes de Estados Unidos, y sólo en casos específicos como la iglesia Luz del Mundo e Iglesia Apostólica de la Fe en Cristo Jesús, su origen es nacional.

Son varios los problemas metodológicos y prácticos que se enfrentan para conocer con certeza el número de SR locales y nacionalmente. En principio, todas las SR en el país tienen la obligación de registrarse en la Secretaría de Gobernación, no obstante, una de las SR más activas por su proselitismo es el caso de La Torre del Vigía de México, A. C., que estaba, hasta 1988, inscrita como "Asociación Civil con Fines Culturales" registrada ante el notario público número 2 de la Ciudad de México, pero que en realiđad se trataba de los testigos de Jehová. Finalmente, esta SR se registró a fines de 1989 ante la Secretaría de Gobernación. Otras SR se registran en la Secretaría de Gobernación con nombres que no precisan con claridad a qué variante dentro del protestantismo pertenecen. En la solicitud de registro del templo Rosa de Saron (en Tijuana), sólo se anota "Grupo religioso Evangelista", tratándose de un grupo pentecostal, También están aquellas SR cuyas prácticas se realizan en pequeños templos escondidos en vecindades o casas particulares, y que no están registradas ante notario público ni con las autoridades correspondientes, éste sería el caso de la Iglesia de la Comunidad Metropolitana.

En cuanto a las organizaciones privadas de beneficencia norteamericanas, las que se definen a sí mismas como organismos "no lucrativos y de servicio social", están integradas mayoritariamente por voluntarios quienes dedican su tiempo, esfuerzo y recursos para ayudar a resolver necesidades específicas de la población. De estas organizaciones no existen censos en el país, ni están inscritas a controladas por autoridad alguna. 


\section{ALGUNAS RAZONES DEL CRECIMIENTO DE LAS SOCIEDADES RELIGIOSAS EN LA FRONTERA NORTE (BAJA CALIFORNIA)}

Una primera explicación simplista del crecimiento de las SR, sería que éste se debe exclusivamente a un proyecto preconcebido del imperialismo norteamericano, si bien no existe un proyecto global de todas las SR para "invadir" América Latina, sí obedece a la dinámica de expansión del sistema capitalista de dominación. No obstante, el crecimiento de las SR en la frontera no sólo es resultado de factores externos sino también internos, los que tienen un peso fundamental.

a) Externos. El alto incremento del protestantismo sectario a partir de los años setenta de Estados Unidos hacia América Latina; la multiplicación de las grandes organizaciones evangélicas interdenominacionales, las cruzadas evangélicas nacionales e internacionales (Valderrey, 1985:22). La vecindad de Baja California con el estado de California, lugar donde existe un importante crecimiento de SR, hacen de la frontera el mercado "espiritual" más cercano de un país subdesarrollado; California es la sede de numerosas SR matrices, y Baja California el mercado inmediato de adeptos potenciales. Otro elemento son los medios de comunicación norteamericanos con mensajes religiosos, los que empiezan a tener una importante presencia en el espacio fronterizo (Clark, 1988b).

b) Intemos. La crisis social, política y económica que enfrentan amplios sectores de la población ha creado una demanda religiosa producto de situaciones de angustia, temor e inseguridad; demanda que está tratando de ser satisfecha por SR, llenando así espacios vacíos dejados por la Iglesia Católica.

Para Valderrey ésta es una razon de importancia fundamental:

La permanente y progresiva crisis global estructural, por sucesivos agotamientos de los distintos modelos de dominación, ha creado las condiciones más propicias para el surgimiento y la multiplicación de las sectas pentecostales que inundan los barrios, las ciudades y los campos de Centroamérica (1985:23).

La dinámica migración pone a disposición de las SR un ejército de reserva espiritual; carente de una sólida formación religiosa católica; sociedades religiosas que en sus respuestas están dando cohesión social a sectores específicos de la población, Por ejemplo, la Iglesia de la Comunidad Metropolitana dirige su atención a homosexuales y lesbianas, abriendo un espacio religioso a un segmento de la población que no es aceptado abiertamente por otras SR. El Centro Cristiano la Puerta (pentecostal), fundado en 1983, con una membresía aproximada de 110 adherentes (hasta 1986) e integrado en un $80 \%$ por cholos, alcohólicos y ex drogadictos, 
quienes al no encontrar otras alternativas en SR que los aceptaran conservando su cultura chola, hallan en esta SR apoyo y comprensión, facilitándoles contactos con grupos de cholos y chicanos conversos en California y Arizona, lugar este último donde se fundó la SR con el nombre de "Victory Chapel". Todas éstas actualmente cuentan entre sus filas con altos porcentajes de hispanos, población a la que orientan su trabajo en Estados Unidos.

Para el profesor J. Huegel, del Union Theological Seminary, la puerta de entrada más efectiva de México es la frontera norte, por las siguientes razones:

1) La migración temporal, pasada y presente, a/y de Estados Unidos; 2) sequía y presiones económicas que empujan a la gente en grandes números a la economía del dólar a lo largo de la frontera; 3) la influencia de los estados del norte sobre el interior de México; y 4) el crecimiento de nueve centros urbanos importantes a lo largo de la frontera (citado en Read, et al., 1969:173).

En México el mayor crecimiento de las SR se localiza en las fronteras norte y sur, y en los principales centros urbanos del país.

En Tijuana hay una alta actividad religiosa expresada en una variedad de SR, que ponen a disposición del fronterizo la oportunidad de seleccionar de acuerdo con sus necesidades personales. La diversidad de SR ha pasado a formar parte fundamental de la realidad social y cultural fronteriza.

\section{LAS SOCIEDADES RELIGIOSAS Y LA MIGRACIÓN}

La migración a la frontera norte juega un papel clave en el proceso de difusión de expresiones religiosas. Se trata de una migración interna e internacional, compuesta mayoritariamente por católicos, muchos de ellos campesinos. Esta situación ha permitido que los migrantes convertidos a otras religiones, pocos en su lugar de origen, los más en la frontera o en Estados Unidos, al regresar a sus pueblos como nuevos adherentes a otra SR, como pastores o misioneros se conviertan en agentes de difusión de "las buenas nuevas" o ayuden a fundar templos. La migración plantea ventajas a las SR, que son aprovechadas en ambos lados de la frontera. Pone a su disposición un ejército de reserva espiritual potencial y permanente de clientela religiosa, que a diario se renueva e incrementa por efectos de la migración y del crecimiento natural de la población fronteriza. Otras ventajas para las SR son las posibilidades de reclutamiento en ambos lados de la frontera. La siguiente descripción de la Iglesia del Nazareno, ejemplifica los beneficios de la migración.

Un grupo de jóvenes mexicanos fueron convertidos en Texas y estudiaron en el Nazarene Bible Institute en San Antonio. A su 
regreso a México, se convirtieron en los líderes de una generación de fundadores de iglesias, quienes han establecido una de las más vigorosas iglesias en México (Read, et al., 1969:172).

El programa bracero (1942-1964), y anteriormente el éxodo de compatriotas a Estados Unidos a fines del siglo pasado y durante el período revolucionario, facilitó la conversión religiosa de miles de mexicanos que laboraban en campos agricolas norteamericanos propiedad de protestantes, en donde muchos, por primera vez, escucharon hablar del evangelio fuera de la iglesia católica a la que pertenecían. Ocasionalmente visitaron templos protestantes o fueron visitados por evangelistas, quienes les obsequiaron el Nuevo Testamento en español. Una de las primeras iglesias beneficiadas con la migración fue la bautista:

Bautistas y otros misioneros han reportado caso tras caso de miembros de sus iglesias que ha hecho uno o más viajes a Estados Unidos bajo el programa bracero, quienes primero encontraron a Cristo como su salvador, mientras atendían iglesias evangélicas en Estados Unidos (Read, et al., 1969:171).

California, destino de miles de migrantes latinoamericanos principalmente mexicanos y centroamericanos, se ha convertido en un estado con alta participación de las SR en comunidades hispanas. Debido al alto crecimiento de la migración, la Iglesia Apostólica de la Fe en Cristo Jesús, en la década de los sesenta, había logrado establecer más de 50 iglesias hispanoparlantes en California (Read, et al., 1969:168).

Iglesias y templos con nombres diversos van apareciendo aquí y allá en los barrios latinos: Iglesia Bautista Nueva Jerusalén, Iglesia Evangélica Latina, Primera Iglesia Bautista Mexicana, Iglesia de Dios Latino Americana, Templo Calvario (Asamblea de Dios), Templo la Hermosa (pentecostal). En el este de Los Ángeles hay ahora numerosas calles con templos, a una de las cuales la hemos bautizado como "el wall street de la religión". Este crecimiento de templos y SR refleja una intensa actividad proselitista, en la que grupos pentecostales, principalmente evangélicos, bautistas, testigos de Jehová, mormones y adventistas del septimo día, se disputan el espacio religioso latino, hasta ahora dominado por la Iglesia Católica. Aproximadamente el $80 \%$ de los 20 millones de hispanos en Estados Unidos son católicos.

Otro de los factores que más influye para que las SR atraigan adeptos entre los hispanos migrantes es un vacío de evangelización de la fe católica en sus lugares de origen, complementado con una pobre instrucción formal de la doctrina católica. 
La penetrante actividad de las SR es ahora preocupación del clero católico californiano. En abril de 1984, obispos, secerdotes y religiosos que trabajan con hispanos, se reunieron para analizar las razones por las cuales éstos son atraídos por los grupos protestantes; sus conclusiones más importantes fueron:

Un uso efectivo de la biblia; estudios biblicos; distribución de folletos y biblias traducidas al español; una relación personal, comunitaria y apostólica, utilizando pequeños templos; grupos de oración; visitas domiciliarias; servicios sociales, extendiendo su trabajo a pandillas, ex prisioneros y trabajadores migrantes en el campo; la utilización de programas de radio y televisión; de actos litúrgicos similares a la misa católica, y de posiciones anticatólicas en muchas de las sectas, en contra del celibato, imágenes y devoción a la virgen María. La resolución del clero católico, fue adoptar una actitud positiva, no desafiando a las sectas, y reforzar la evangelización directa entre hispanos.

Otros elementos que coadyuban a la expansión de los GR son: el empleo de pastores hispanos, lo que ha motivado al clero católico a incluir sacerdotes bilingües; la oportunidad de los fieles de convertirse en ministros en uno o dos años, asistiendo a una escuela biblica, incrementando de esta forma el número de pastores; a diferencia de los católicos, quienes enfrentan escasez de vocaciones y un largo periodo de preparación para ordenarse, además de la carencia de sacerdotes católicos entrenados para trabajar en parroquias hispanas (Sly, Julie. The Tindings, 8 de febrero de 1985).

Como observamos, los migrantes encuentran en California y en la frontera mexicana alternativas religiosas que no tenían generalmente en sus pueblos, lo que, complementado con su falta de preparación católica y una menor presión cultural y socioreligiosa que sancione su pertenencia a la iglesia católica, los presenta como candidatos a ser reclutados por cualquiera de las SR, que logre convencerlos.

\section{SOCIEDADES RELIGIOSAS ENEL MEDIORURAL: SAN QUINTÍN, BAJA CALIFORNIA}

La presencia de SR se ha ido extendiendo también al medio rural de Baja California. San Quintín, a sólo 300 kilómetros de la frontera, es un ejemplo. Aquí las SR más activas son los pentecostales, pero existen también otras formas religiosas no presentes en las zonas urbanas, como los mormones polígamos ${ }^{5}$ pertenecientes a la iglesia Church of the First Born of the

5 Estos mormones polígamos no están reconocidos oficialmente por la Iglesia de los Santos de los Úlitimos Días, quienes por cierto en el pasado, igualmente, practicaron la poligamia. Se calcula que en la actualidad existen de 20 a 50 mil mormones polígamos, distribuidos en los estados de Utha, Arizona, Idaho, California, otros estados del oeste y México. 
Fulness of Times, mejor conocidos como "lebarones" en honor a su fundador de apellido LeBaron, asesinado en Ensenada en 1972. Con apoyo del Estado, fundaron en San Quintín su comunidad, el ejido Zarahemla.

Como resultado de sus esfuerzos una gran porción de tierra fue donada por el gobierno para el establecimiento del ejido de Zarahemla el 16 de agosto de 1974 (...) Cuando el gobernador de Baja California, Milton Castellanos Everardo, vino a Los Molinos a inaugurar el nuevo ejido, el hermano Pérez estaba allí para recibirlo. Fue con justificable orgullo que el hermano Pérez le mostró al gobernador el cuarto para el cuidado de los niños y jardines que se levantaron como prueba de la industria de ese pequeño pueblo. Las mujeres de la colonia le obsequiaron al gobernador una hermosa colcha bordada hecha a mano, para su esposa (LeBaron, 1981:257).

Lo significativo de la expansión de las SR es el momento histórico y el contexto socioeconómico en que éste se produce. El crecimiento de las SR en San Quintín no ha sido casual, coincide con la llegada masiva de indígenas a fines de los setenta; el surgimiento de una agroindustria con participación de transnacionales asociadas a capitales regionales, creando una nueva regionalización económica que convirtió a San Quintín en el centro productor agrícola más importante de Baja California en la costa del Pacífico; el posterior desarrollo de procesos de organización sindical autónomo, a partir de 1984, a través de la Central Independiente de Obreros y Campesinos (CIOAC); y consecuentemente el surgimiento de conflictos sociales, derivados de las demandas de los trabajadores, resultado de las condiciones prevalecientes de explotación, situación que llegó a convertirse en uno de los problemas políticos más graves de la región (1984-1987) (Clark, 1988a).

Los jornaleros son en un $85 \%$ indígenas mixtecos, principalmente zapotecos y triquis provenientes de Oaxaca, que en conjunto suman más de 20 mil habitantes y en épocas de cosechas la cifra se duplica. Explotados como mano de obra barata, sus condiciones de vivienda, salud y alimentación son precarias. A partir de 1984 los trabajadores encontraron otra alternativa de organización a través de la CIOAC, sindicato fuera del control del Estado y de los sindicatos oficiales (Confederación de Trabajadores Mexicanos, Central Campesina Independiente y Central Nacional de Campesinos). El Estado y el capital han obstaculizado a este sindicato en su desarrollo, el primero, entre otras maniobras, negándole el registro legal; y los segundos despidiendo $\mathrm{y} / \mathrm{u}$ hostigando a los trabajadores afiliados a la CIOAC o encarcelando a sus líderes con falsas acusaciones. 
En este amplio valle, miles de trabajadores y sus familias viven en verdaderos "campos de concentración", cercados con alambres de púas y algunos con guardias armados, con el propósito de impedir la entrada a los dirigentes de la CIOAC, intentando cancelar así mayores posibilidades de organización (Clark, 1987). Es éste el escenario donde el elemento religioso juega un rol importante, la entrada a los "campos de concentración" está prohibida a las organizaciones sindicales independientes, pero no a las SR norteamericanas. Por ejemplo, en el campo La Loma del Mar, propiedad de los hermanos Canelo, poblado en temporada de cosechas por más de 4,000 jornaleros incluyendo a sus familias, es visitado diariamente de 7:30 de la mañana a 4:30 de la tarde, por un grupo de fundamentalistas "cristianos renacidos" provenientes de Canadá y Estados Unidos, quienes realizan labores de proselitismo que incluyen: prácticas de beneficencia a través del obsequio de ropa y alimento chatarra, distribución de literatura, pláticas, proyección de películas, visitas familiares, y un gran énfasis en el trabajo religioso con los niños indígenas, a los que llevan en grupos a pasar fines de semana en el orfanatorio que han instalado en el valle. Este proselitismo no ha sido bien visto por otros indígenas, e incluso, ha provocado conflictos:

Llegaron a predicar como cinco americanos y tres mujeres, y no hablan el español, sólo uno lo habla medio mocho y iba uno de Oaxaca, un paisano, y comenzaron a predicar sobre lo que ellos predican, sobre el evangelio, pero yo creo que el patrón los dejó entrar, eran una "bleizer" y una panel, aunque hay un letrero que dice "se prohibe la entrada a toda persona sin negocio". Estuvieron predicando, casi no se juntó gente, ya que casi toda la gente es de religión católica, y cuando iban a salir, los apedriaron y se quedaron como tres gabachas adentro de la panel y salieron huyendo (Fernando García, comunicación personal 1985).

En una campaña realizada en 1984 por grupos fundamentalistas, distribuyeron cientos de volantes donde pedían que los niños no asistieran a clases, ya que los profesores "no enseñaban la palabra de Dios". Ante esta ofensiva religiosa la CIOAC elevó su protesta a las autoridades, por lo que consideraban "un atentado a la vida social del país".

Anterior a la fundación de la CIOAC en el valle, los hermanos Canelo, los latifundistas más poderosos de San Quintín, por medio de sus mayordomos sugerían a los trabajadores que "tenían que ser 'hermanos' para poder trabajar con ellos", los campesinos posteriormente se quejaron ante la CIOAC, iniciando ésta "una labor de concientización con los trabajadores para que vieran cual era la realidad", afirma Benito García indígena y líder del sindicato. No obstante estas circunstancias, las SR empezaban a tener éxito con su tarea proselitista: 
Hay muchos paisanos que ya se han convertido, muchos están en el ejido Zapata, allí compraron un terreno grande, fue un paisano que fue a Estados Unidos a trabajar, juntó dinero y se vino y lo ayudaron los americanos a hacer una iglesia y hicieron como un pueblito y lo cercaron, y la iglesía parece tipo americano, y las casas donde viven son de cartón, de lámina negra, hasta un poquito peor que la de los campos (Fernando García, comunicación personal, 1987).

En 1986 había alrededor de 12 templos, exceptuando los católicos, distribuidos en el valle de San Quintín. Hasta 1989 la iglesia católica contaba con tres sacerdotes franciscanos y tres templos en el valle. De acuerdo con Benito García, éstos no tenían un compromiso social con la problemática de los campesinos:

Todo el contenido a fondo de su palabra, coincide con el poder económico de los patrones, durante los sermones dominicales, nos dicen que no podemos tener envidia de otros, porque si otros tienen es porque Dios quiso, que es natural que el hombre tenga que sufrir.

Los intereses económico-político-religiosos están íntimamente interrelacionados, los dos primeros explotando y manipulando la mano de obra, y los últimos reforzando estas actitudes a través de su acción y discurso religioso. Hasta ahora ninguna SR, incluyendo la católica, ha alzado su voz para denunciar la injusta situación de los trabajadores, y menos aún tratado de crear conciencia de su realidad. Las SR han encontrado en el valle un campo fértil como la tierra misma, por un lado simpatía del capital, una iglesia católica débil, migrantes cuyo número aumenta, y la cercanía con Estados Unidos. Las SR proporcionan el soporte ideológico que sirve de base y apoyo para explotar con mayor facilidad a los jornaleros conversos; y al Estado le permite garantizar al capital transnacional la tranquilidad y paz social necesarias para la producción.

\section{LA EDUCACIÓN: EL CASO DE LOS TESTIGOS DE JEHOVÁ}

Una de las manifestaciones más evidentes de la presencia de SR se refleja en las aulas escolares a través de los estudiantes (de primaria y secundaria), particularmente testigos de Jehová, ${ }^{6}$ quienes se niegan a realizar honores a la bandera y a cantar el himno nacional. Esta conducta toca aspectos muy sensibles del nacionalismo mexicano: los símbolos patrios;

6 Para una descripción etnográfica de los testigos de Jehová, consultar a Brenda J. Mann, (1972:157-168). 
lo que da lugar a preguntas acerca de la lealtad del grupo, y su compromiso con los principios básicos nacionales. Lo que sucede es que su interpretación bíblica no coincide con las prácticas cívicas mencionadas. Este problema no se presenta en las escuelas preparatorias o universitarias, donde no realizan asambleas o reuniones en las que el alumno se vea comprometido a celebrar los honores correspondientes. Este problema se ha tratado útimamente en la nota periodística, quejas constantes del sistema educativo, funcionarios, padres de familia y clero católico sobre este problema. Últimamente las reclamaciones se extienden igualmente a profesores pertenecientes a los testigos de Jehová. Con el propósito de conocer más de cerca esta realidad, entrevistamos a profesores y personal administrativo pertenecientes a tres niveles escolares diferentes: una escuela primaria del sistema de educación federal, una escuela secundaria técnica del sistema de educación estatal, y una secundaria privada. Si bien es cierto que ésta no es una muestra representativa, por lo menos nos da pistas para analizar el problema.

1) Escuela primaria (sistema federal). En los últimos años los profesores empezaron a notar con preocupación que varios de sus alumnos, en las asambleas semanales, no celebraban los deberes cívicos ya que su religión lo prohibía. Una profesora entrevistada tenía entre sus alumnos del tercer grado a dos testigos de Jehová quienes, a diferencia de otros, sí realizaban los deberes correspondientes, según la profesora debido a que "no están completamente adoctrinados en ese sentido". El profesorado considera a los pocos alumnos testigos de Jehová, como "excelentes" o "muy buenos alumnos". Los días en que realizaban las asambleas estos estudiantes preferían ausentarse para evitar conflictos. La Secretaría de Educación Pública (hasta 1985) optó por solicitar a los maestros reportar a la dirección del plantel, los nombres de los estudiantes que se rehusaran realizar dichos deberes, que a su vez los enviaba a las autoridades superiores. Algunos profesores se abstuvieron de denunciar a sus alumnos, por considerarlo injusto ya que se trataba de los mejores, Las autoridades educativas en sus declaraciones hablaban de instrumentar medidas para expulsar alumnos, situación que de hecho se presentaba en algunas escuelas:

Alumnos y maestros de las diferentes instituciones educativas, que no se ajusten estrictamente al artículo tercero de la Constitución Política Mexicana, en el sentido de que la educación es laica; serán expulsados de las escuelas, lo cual constituye una de las acciones concretas que ha implementado la Unidad de Servicios Educativos a Descentralizar (USED) de Baja California, para contrarrestar la proliferación de sectas religiosas que atenten contra los 
símbolos patriso [...] paralelamente se ha emprendido una serie de eventos con los que se reafirman nuestros valores culturales y símbolos patrios [...] el problema es grave, lo rechazamos y lo combatiremos de una manera tajante $(A B C, 15$ de febrero de 1985).

2) Escuela técnica (sistema estatal). Esta escuela cuenta con una población de 250 alumnos de los cuales, de acuerdo con el director, el $10 \%$ aproximadamente, son testigos de Jehová; todos considerados como "muy buenos estudiantes". Ningún empleado docente o administrativo era miembro de la secta. En 1985 las autoridades educativas les ordenaron, que todo estudiante de nuevo ingreso debería firmar el siguiente documento, que lo comprometía a cumplir con los deberes cívicos so pena de ser expulsado:

Yo (nombre del alumno), al pretender mi ingreso como alumno numerario de esta escuela a su cargo, declaro:

Que estoy plenamente enterado de mis obligaciones elementales como mexicano, ante la significación de los símbolos de mi nacionalidad así como de los deberes que adquieren los alumnos de planteles como éste, sobre la actitud que han de guardar ante la Bandera y el Himno y el Escudo de México. Por lo que de la manera más conciente, manifiesto:

Que me comprometo a saludar a la bandera nacional, a cantar nuestro himno patrio y a respetar el escudo de México, en todas las ceremonias en que se les rinda homenaje y a venerarlos en todo lugar y en todo momento, así también a que se me dé de baja inmediatamente si me aparto de este compromiso.

Varios estudiantes testigos de Jehová firmaron el documento; otros se dieron de baja, y se dio el caso de una joven que se negó a firmarlo, ya que, por razones religiosas no estaba dispuesta a cumplirlo por lo que no fue aceptada.

3) Escuela secundaria (privada). Estudiantes testigos de Jehová que fueron expulsados de sus escuelas, encontraron instituciones que se habían ido especializando en recibir a "estudiantes rechazados". En esta secundaria el $50 \%$ de los alumnos eran testigos de Jehová "que han sido corridos de otras escuelas porque no celebraban los deberes cívicos". Aquí les toleran que estén presentes en las actividades cívicas, aunque no saluden a la bandera o canten el himno nacional.

No existe homogeneidad en el acatamiento de las disposiciones que ordena la Secretaría de Educación Pública. En las tres escuelas visitadas se adoptaban actitudes distintas: desde reportar al estudiante, obligarlo a firmar documentos o tolerarlo; mientras que en la secundaria particular 
aprovechaban la "demanda de estudiantes rechazados", con la condición de estar presentes en los eventos cívicos. Lo más preocupante son las medidas adoptadas por el Estado en contra de los "estudiantes rechazados", situación que les reafirma su convicción religiosa de "pueblo perseguido", de acuerdo con sus propias interpretaciones bíblicas, y propicia una psicología de la persecución. Estos estudiantes se encuentran en medio de dos fuerzas: una, el adoctrinamiento religioso de su secta; otra, el ataque verbal continuo del clero católico y la presión del Estado, cuyas acciones van directamente en contra de los miembros más vulnerables de la secta, los menores de edad, quienes sólo cumplen las enseñanzas de los adultos miembros de su organización.

¿Cómo han solucionado los testigos de Jehová el problema educativo? Para resolverlo, han implementado varios mecanismos en el nivel de primarias: "Nosotros mismos les enseñamos el equivalente, además contamos con la ayuda de colaboradores, es decir de compañeros que tienen más tiempo disponible para realizar esta actividad de educación" (testigo de Jehová, comunicación personal, 1985).

Para alumnos rechazados en primarias y secundarias también utilizan el sistema oficial de educación abierta, con el propósito de obtener los certificados expedidos por la Secretaría de Educación Pública. La ventaja de este sistema es que no se realizan los deberes cívicos. Contaban además en la península de Baja California, para 1985, con alrededor de 80 centros de alfabetización; y consideraban las acciones de las autoridades educativas "como una violación a los derechos humanos". Seguramente, la solución que en el futuro encontrarán será la misma adoptada en Estados Unidos, donde también han tenido problemas educativos: abrir sus propias escuelas.

\section{Los testigos de Jehová y otras sociedades religiosas: su activismo y proselitismo}

\footnotetext{
"En esta casa somos católicos no queremos oír el mensaje de los testigos de Jehováni de los mormones, ni de nínguna otra secta, porque nos anuncian un evangelio distinto al que hemos recibido", (Texto de un volante que distribuyc la Iglesia Católica, para ser pegado en las puertas de las casas).
}

Unos de los aspectos al que más tiempo y esfuerzo dedican las SR, con diferente intensidad, es al proselitismo. Todas las SR están involucradas en una competencia abierta por atraerse nuevos miembros fuera de su grupo o retener a los propios. Hay SR cuyo proselitismo se realiza en amplias zonas de la ciudad; otras concentran su atención en determinadas áreas, de 
acuerdo con sus recursos y estrategias, y en ocasiones se respetan territorios con la intención de no competir entre sí.

Según el Censo general de población de 1980, los católicos representaban el $92.6 \%$ de la población total del país, frente a un $7.4 \%$ que correspondia a los no católicos. De la mayoría católica es de donde reclutan adeptos las demás SR debido, según el delegado apostólico de la santa sede en México:

A la ausencia de sacerdotes, y a la falta de formación de católicos, que por falta de doctrinamiento se convierten en "victimas de pastores protestantes" que (...) la mayoría de las veces cobran adeptos por medio del estómago ( $A B C, 29$ de abril de 1985).

De acuerdo con un estudio de la Diócesis Católica de Tijuana, la existencia de una "grande influencia" y proselitismo de grupos no católicos se debe a la proximidad con los Estados Unidos y a la actividad que realizan con la población. De 17 SR con las que realizamos trabajo de campo, los Testigos de Jehová y la Iglesia de Jesucristo de los Santos de los Últimos Días, mejor conocidos como mormones, eran quienes realizaban un proselitismo más agresivo:

Ambos grupos, tradicionalmente están empeñados en una vigorosa conversión y en actividades misionales. Esto es, ellos explícitamente rechazan el concepto de pluralismo que incluye el respeto para la autonomía de cualquier grupo y el derecho a ser y escoger, es decir una agresiva posición que evidentemente estimula resentimiento (Johnstone, 1975:238).

Comparados con otras SR menos activistas, por ejemplo, con los Espiritualistas Trinitarios Marianos, quienes no distribuyen literatura ni obsequian artículos o realizan visitas domiciliarias, sólo se concretan a la difusión que corre de boca en boca por medio de sus miembros y simpatizantes.

Existe una evidente preocupación del clero católico por el avance de las sectas y los grupos protestantes, localmente la diócesis realiza campañas y obras para afianzar el catolicismo:

Berlie (obispo) está empeñado en esta nueva cruzada - o como dijera, en la nueva forma de entrarle al toro- y para ello ha llamado a cientos de estudiantes de secundarias y preparatorias para enviarlos al apostolado en las colonias (principalmente en la Pancho Villa y el cerro Colorado donde hay más testigos de Jehová (...) ahora va la reconquista de los católicos por los testigos de Jehová (Zeta, 5-12 de octubre, 1984).

A nivel nacional, en la reunión de la Conferencia Episcopal Mexicana celebrada en 1985, dedicaron la mayor parte del tiempo al tema del proselitismo, haciendo un llamado a "todos los sectores del país a unirse 
anteel avance de las sectas protestantes", en otra parte de sus declaraciones, manifestaron los obispos que "sospechaban" que las sectas dividen al país, que con su enorme poder económico compran al pueblo, que prohíben los honores a la bandera y que mediatizan a la población "ya que sólo le piden alzar los ojos al cielo, con lo cual la enajenan y la hacen olvidarse de sus problemas materiales". Afirmaron que algunas sectas llegan a disponer que, aun en caso de enfermedad grave, no se recurra a las transfusiones de sangre y medios quirúrgicos. Al pedirles que concretaran sus acusaciones, adujeron "que no tenian datos concretos al respecto que son sólo sospechas". Estas aseveraciones ambiguas sin hacer señalamientos concretos, dejan una sensación generalizada de que lo afirmado sucede con todas las SR, lo que es falso y tendencioso, reflejando falta de conocimiento de la realidad religiosa extra católica. En la citada reunión se acordó enfrentar a las sectas utilizando "la estrategia de los protestantes, para neutralizar, manejar y ganar competitivamente la guerra en contra de las sectas protestantes" (La Jornada, 20 de abril de 1985).

Desde la perspectiva anterior, el problema se reduce a una mera competencia por el dominio del campo religioso, en la que están involucradas todas las SR, sobresaliendo los testigos de Jehová por su agresivo proselitismo, basado en técnicas de mercadotecnia de la venta del producto puerta por puerta, de la insistente visita domiciliaria y la distribución de literatura, pero nunca del obsequio material:
Comonorma, en términos generales se tardan los hermanos tres meses aproximadamente dándole la vuelta a toda la zona, que pueden tratarse de dos o tres colonias. La labor la hace una compañía compuesta de 30 a 70 personas (testigo de Jehová, comunicación personal, 1985).

De esta forma, en pocos días tienen un panorama general de la colonia visitada y con quiénes habrán de insistir más para convertirlos. Esta estrategia les ha dado la imagen de ser un grupo bastante numeroso, de realizar un proselitismo agresivo, aunado a la gratuita publicidad del clero católico y el Estado quienes hacen frecuentes referencias a esta OR, haciéndolos aún más populares. Para 1986, de acuerdo con los datos estadísticos de los testigos de Jehová, eran en el país 151,806 miembros (Watch Towel Bible, 1985), y para 1987 eran 209,000 (testigo de Jehová, comunicación personal, 1984); según un alto funcionario religioso de este grupo, en Baja California se encuentran concentrados en Tijuana, el resto en Mexicali y con menores porcentajes en Tecate y Ensenada. Un aspecto que resalta son las cifras exageradas que da el clero católico local: "Tenemos 70,000 en Tijuana y por lo menos unos 150,000 en todo el Estado, dice con tristeza el obispo" (Zeta, 5-12 de octubre de 1984). 
Hasta ahora los testigos de Jehová han mantenido en el país un total silencio como respuesta a los ataques de que son objeto.

\section{Otras sociedades religiosas}

Hasta la frontera ha llegado el Instituto Lingüístico de Verano (ILV), lo que no nos sorprende, ya que parte de su labor en el país la ha realizado con indígenas oaxaqueños, quienes emigran en grandes cantidades a Baja California. En Tijuana, en la comunidad de mixtecos (de la colonia Obrera tercera sección), el ILV tiene una representante norteamericana, ${ }^{7}$ dedicada a actividades de proselitismo religioso, venta y distribución de literatura (biblias, gramáticas, cuentos). Lo anterior nos indica que el ILV no sólo se ha concretado al medio rural donde tradicionalmente ha venido trabajando, sino que continúa su labor en los lugares de destino de los migrantes indígenas, en este caso mixtecos. El ILV ha sido denunciado en inumerables ocasiones por antropólogos, sacerdotes y funcionarios, ya que su actividad en América Latina:

No sólo contribuye a atomizar las lenguas indígenas, sino ha evitado la comunicación efectiva de los mismos en la elaboración de una actitud política unificada. Más todavía, al introducir los esquemas del protestantismo anglosajón, el ILV ha contribuido a la división y a la violencia entre las comunidades indígenas (Colegio de Etnólogos y Antropólogos Sociales, 1979:2).

Tijuana, al igual que el resto de la frontera, se ha convertido en un atractivo mercado para el proselitismo, propiciando una intensa actividad religiosa que muestra la capacidad organizativa y de movilización de distintas SR. Tan sólo en el lapso de un mes (del 7 de abril al 11 de mayo de 1986) asistimos a siete reuniones y campañas masivas de evangelización: católicos "Pascua Juvenil" aproximadamente 5,000 asistentes, duración un día; diversos grupos protestantes, "Campaña de Evangelización, Nuevas de Gran Gozo Para Todos", alrededor de 500 asistentes diarios, duración cuatro días; Centro Cristiano "La Puerta" (pentecostal), "Cruzada de Milagros y Sanidad", más o menos 140 asistentes diarios, duración cinco días; Renovación Cristiana del Espíritu Santo (católicos carismáticos), "VI Encuentro Regional de Baja California", aproximadamente 2,000 asistentes primer día, cerca de 4,000 asistentes segundo día y alrededor de 5,000 asistentes tercer día; Camps Farthest

7 Casualmente, esta norteamericana es la misma que durante varios años trabajó en San Jerónimo Progreso, en la Mixteca Baja, pueblo del que hay una mayoría en la colonia Obrera tercera sección. 
movimiento Cristo céntrico no afiliado a ninguna denominación", duración un día; Grupo Protestante "Gran Campaña Evangélica, Cristiana Unida", duración siete días; Metodista y otros grupos protestantes, "Gran Concentración Evangelista", duración un día.

Las reuniones anteriores, citadas textualmente como anunciaba su publicidad excepto por la anotación en paréntesis, son un indicador del movimiento religioso masivo en la ciudad, del que participan asimismo norteamericanos como pastores, oradores o cantantes.

El activo proselitismo en ambos lados de la frontera, tanto en la comunidad hispana de California como en Baja California, provocó que los obispos católicos de ambos estados elaboraran un documento sobre el tema manifestando su preocupación sobre el mismo; exhortando a la comunidad católica ante las "avanzadas misioneras, de otros grupos no católicos"; y afirmando que en ningún momento deseaban "agravar la situación poniéndonos en competencia con otros grupos religiosos" ( $\mathrm{Co}$ misión Episcopal Alta/Baja California, 28 de febrero de 1990).

Después de inumerables solicitudes de expulsión, el ILV, por orden presidencial, debió haber abandonado el país en 1983; sin embargo, se expande ahora a centros urbanos de la frontera norte, destino importante de indígenas migrantes. Causalmente, una de las filiales del $\mathrm{ILV}$, el Wycliffe Bible Translators, se localiza en Glendale, Califomia, muy cerca de Baja California.

La frontera mexicana es el escenario de una intensa actividad proselitista, que se inscribe en una década histórica (1980) en que el pentecostalismo en Estados Unidos cobra un auge importante y se expande a América Latina; al tiempo que en México se da una grave crisis política, social y económica que crea condiciones intemas para su desarrollo.

\section{BENEFICENCIA Y ASISTENCIALISMO}

Tijuana recibe un promedio de 20 millones de visitantes anuales, la mayoría norteamericanos con propósitos turísticos; y otros pertenecientes a organizaciones privadas de beneficencia (OPB) no religiosas y religiosas, mejor conocidas en Estados Unidos como Charity groups, cuyas prácticas sociales se dirigen a: orfanatorios, hospitales, cárceles, penitenciarías y colonias populares; donde su presencia se ha vuelto cotidiana. Su número es difícil de precisar ya que no existen censos o registros.

Las OPB provienen de una sociedad altamente industrializada y desarrollada, y sus beneficiarios constituyen los sectores sociales más pobres de un país subdesarrollado.

Para una sociedad avanzada e industrializada como la norteamericana, las posibilidades de donaciones materiales son inagotables, ya que existen 
altos niveles de consumo con el consecuente nivel de desperdicios materiales. Miles de toneladas de artículos usados son desechados, vendidos u obsequiados a instituciones de beneficencia. Tijuana, por su situación geográfica al igual que el resto de las poblaciones fronterizas, utiliza muchas de las "sobras" de Estados Unidos: ropa, automóviles, muebles, madera, llantas, etcétera; es decir, nutre su economía de los artículos norteamericanos de segunda. Esta circunstancia es aprovechada también por las OPB y SR quienes las incluyen en sus donaciones junto con alimentos chatarra y, en ocasiones, artículos nuevos. Los siguientes datos dan una idea de las cantidades en bienes procedentes de Estados Unidos que diariamente cruzan la frontera: el Secretariado Diocesano de la Pastoral Social beneficiaba, en 1985, a 22,000 familias con despensas, de las cuales 1,000 eran de Ensenada, 200 de Tecate y el resto de Tijuana. Lo anterior significó el cruce mensual de 180 toneladas de alimentos donados por SHARE, una organización de la Diócesis Católica de San Diego que recibe alimentos chatarra del gobierno americano, donaciones de supermercados y dinero de particulares. La característica del proyecto es tratar de evitar la relación asistencialista a través de un estudio socioeconómico a cada una de las familias beneficiadas con una despensa alimenticia, al tiempo que se les solicita su participación en actividades de su parroquia (Sacerdote Miguel Ángel Betancourt, comunicación personal, 1986).

Las OPB y SR funcionan como un medio de redistribución, a las sociedades más desheredadas, de excedentes económicos y materiales de una sociedad mejor provista. La oferta religiosa se complementa en muchos casos con prácticas asistencialistas. Aunque cabe aclarar que ésta no es una actividad practicada por todas las SR, un ejemplo son los testigos de Jehová.

Sectores del clero católico justifican el éxito de "las sectas" por atraerse clientela religiosa al hacer obsequios; no obstante, esta explicación resulta simplista ya que otros elementos tienen mayor peso en la decisión de los adherentes.

Esta práctica ha generado, en la mayoría de los casos, un modelo asistencialista que provoca dependencia, cuyos efectos - aún sin proponerse los donantes- en términos de costos y beneficios van de lo positivo a lo negativo, teniendo en el último de los casos una función no transformadora, ya que se convierte en un paliativo a las necesidades materiales de la comunidad, donde finalmente los "beneficiados" juegan un rol pasivo:

Estas formas asistencialistas, como instrumento de manipulación, sirven de conquista. Funcionan como anestésico. Distraen a las masas populares desviándolos de las verdaderas causas de sus problemas, así como la solución concreta de éstos. Fraccionan a las masas populares en grupos de individuos cuya única expectativa es la de recibir más (Freire, 1983:194). 
Otras variantes de la beneficencia son las OPB dedicadas a funcionar como apoyo a SR; un ejemplo sería Amor Ministry y los grupos informales de estudiantes, clubes sociales, profesionistas, amas de casa, etcétera, que en algún momento se organizan para visitar el México pobre.

Las siguientes son sólo algunas de las 35 OPB que detectamos en Tijuana: Los niños, Clínica primavera, Corazón, Children of the Americas, Serving Hands, Futuro del oro, etcétera (Clark, 1986b). Estas organizaciones se han especializado en alguna o varias prácticas sociales; otras han diversificado sus actividades dirigiéndolas a sectores específicos de la población: cárceles, penitenciarías, orfanatorios, albergues, hospitales, colonias populares e instituciones religiosas. Algunas OPB mantienen representantes en Tijuana como Los Niños (con matriz en San Isidro, California), Responsability y Chidren of the Americas; otras como Amor Ministry o Misioneros de Dios (cuya matriz se localiza en Fullerton, California), han estructurado una elaborada red de prácticas sociales vinculadas a orfanatorios, construcción de viviendas, y un extenso programa de reclutamiento de voluntarios temporales y permanentes; sólo en el verano de 1985 más de 50 grupos trabajaron en sus programas en Tijuana, representando en conjunto aproximadamente 1,000 norteamericanos; en Tijuana construyeron y operan el orfanatorio Ciudad Refugio y en Tecate el orfanatorio Tecate Mission; para 1986 proyectaban la construcción de 100 viviendas en la colonia Anexa Panamericana. En realidad Amor Ministry no es más que una extensión de la Iglesia de Dios, quien se apoya en esta OPB para su trabajo asistencialista.

Las siguientes son las prácticas sociales detectadas entre las OPB y SR en Tijuana (Clark, 1986b):

1. Donación de bienes (materiales y económicos). La más socorrida práctica es la donación de alimentos, ropa y artículos. Aquí incluimos el traslado de agua "tibia" y "caliente" en tanques, para bañar a menores de edad (por parte de Clairmont Emanuel Baptist Church) y el obsequio de agua potable.

Aportaciones monetarias que pueden alcanzar importantes cantidades para la construcción de hospitales, casas, compra de mobiliario para escuelas, pago de servicios médicos, ayuda familiar y sistemas de préstamos monetarios.

2. Mano de obra voluntaria. Aportación voluntaria de mano de obra norteamericana utilizada en la construcción y/o mejoramiento de casas, iglesias, escuelas, mantenimientos de orfanatorios, electrificación y sistemas de agua potable.

3. Actividades recreativas y educacionales. Las primeras incluyen organización de juegos, excursiones y viajes; las segundas; impartición de 
cursos de inglés, primeros auxilios, doctrina religiosa, etcétera; así como becas completas o parciales para estudiar en la localidad o en Estados Unidos. Responsability dedica gran atención a los niños organizando viajes a Disneylandia, Sea World, San Francisco y Nueva York donde cuatro menores pasaron una semana en un aparente "tour promocional", donde fueron presentados como representantes de la pobreza tercermundista, y como prueba fehaciente del trabajo que realizan en la frontera mexicana, razón para que se les siga apoyando económicamente. Al regreso con su realidad en la colonia Anexa Panamericana, estos niños continuaron como todos los días su labor de pepenadores entre trapos sucios, pedazos de vidrio, malos olores y perros tinosos. Como complemento, la OPB imparte clases de inglés, y su educacuón se orienta al american way of life.

4. Servicios de salud. Impartición de cursos y programas de nutrición, planificación familiar, entrenamiento médico, consulta externa, donación y venta de medicinas, traslado de enfermos graves a Estados Unidos, compra de aparatos ortopédicos, construcción de hospitales. Dos ejemplos son el hospital del buen pastor, en San Quintín; y Proyect Concern fundado a principios de los sesenta orientado a la construcción y operación de hospitales; entrenamiento de asistentes médicos y servicios médicos en las áreas empobrecidas de Indonesia, Latinoamerica, África y Estados Unidos.

5. Actividades productivas. Apoyo económico a través de proyectos de desarrollo comunitario. Instalación de tiendas de segunda, organización y financiamiento de cooperativas. Como ejemplo: Clínica Primavera financió una cooperativa de puercos; y Children of the Americas una cooperativa de gallinas, ambos en la colonia Anexa Panamericana.

El criterio utilizado para seleccionar sus áreas de trabajo consiste en escoger aquéllas que a primera vista aparenten ser "las más pobres", como sucedió en la colonia Anexa Panamericana, asentada sobre un ex basurero. La siguiente descripción enumera los pasos previos del grupo Futuro del Oro, para elegir su "lugar de trabajo":

El Dr. James Letcher, un ministro presbiteriano, vino al sur de Califomia en 1967 para servir a la Iglesia East Whittier Presbyterian de Whittier. Trajo consigo el sueño de establecer una misión en México, lo más cercana posible que permitiera a su gente involucrarse; directamente él, no tenía ningún conocimiento del área fronteriza. Seleccionó a una guía competente, May MacMillan, directora de California Branch of Laubach Literacy. Ella ha estado muy activa trabajando en el área de Tijuana por varios años. Llevó al Dr. Letcher a visitar sitios para su misión. El día que visitaron la colonia Lázaro Cárdenas conocieron a Héctor Venegas, presidente de la villa, $\mathrm{y}$ a su esposa Josefina. El señor y la señora Venegas estuvieron 
en la mejor disposición de trabajar con ellos por el bien de la gente.

El Dr. Letcher y la señora McMillan, supieron que éste era el lugar correcto (Good Newsletter, primavera de 1986).

\section{¿Quiénes son los voluntarios?}

Norteamericanos adolescentes y adultos miembros de clases media y alta, quienes por decisión propia, cubriendo personalmente sus gastos, patrocinados por una OPB o iglesia, viajan al tercer mundo con la intención de aportar su trabajo voluntario y conocer de cerca - en un fin de semana, en un verano o en estancias que se prolongan por varios años-, la pobreza tercermundista, representando para unos una distracción, aventura exótica, alivio espiritual a sus pecados o una liberación a las presiones de una sociedad altamente desarrollada.

En años recientes la oferta de jóvenes voluntarios se ha incrementado. Agencias universitarias especializadas en voluntarios, reportan un creciente interés, "más alto en la actualidad que en 1970", de estudiantes por participar en actividades de beneficencia: "Peace Corps, está esperimentando un incremento de solicitantes quienes son estudiantes graduados, una vocero de la organización caracteriza a la mayoría como 'realistas idealistas'." (Times, 16 de marzo de 1987).

El número de voluntarios norteamericanos en el extranjero, enrolados en grupos evangélicos misioneros, también ha crecido en los últimos años. A partir de 1960, el predominio de los grupos misioneros lo empezaron a tener los evangelistas y fundamentalistas. Para 1987 la Convención Bautista del Sur, contaba con la cifra récord de 39,309 misioneros norteamericanos y canadienses; la North American Protestant Foreign Legion, incluyendo voluntarios trabajadores por menos de un año, sumaban 67,242 , en contraste con los 9,124 católicos, lo anterior significó el patrocinio de 764 misiones, que en conjunto combinaban un ingreso de 1.3 billones de dólares anuales, provenientes principalmente de donaciones (Times, 16 de febrero de 1987).

Dentro del voluntariado hay verdaderos profesionales con un extenso curriculum de trabajo en el tercer mundo, siempre inscritos en OPB o misiones religiosas quienes se han encargado de enviarlos al "sitio adecuado".

Un caso que ejemplifica el perfil típico del voluntario comprometido, y su proceso de incorporación a una vida dedicada a la beneficencia dejando atrás las comodidades de la burguesía, es el doctor Jim Turfin fundador del Proyect Concern, quien hace 25 años inició sus visitas a Tijuana.

Voluntaria y repentinamente el doctor Turfin abandona junto con su familia la exclusiva isla californiana de Coronado para irse a vivir a Hong 
Kong y posteriormente a Vietnam, fundando la organización Internacional Proyect Concern, y años después convertirse en la Fe Baha'ie.

A pesar de las buenas intensiones de quienes forman esa masa heterogénea de voluntarios (amas de casa, estudiantes, jubilados, religiosos, profesionistas, etcétera), al concluir su práctica algunos abrigan sentimientos de frustración, por no haber podido cambiar la sociedad. Un voluntario entrevistado en Tijuana, después de un año de hacer labor, regresó a su país con altos niveles de frustración, al darse cuenta de que su trabajo y el de su organización (Los Niños) no transformaba la sociedad y sólo fomentaba relaciones asistencialistas.

Las OPB funcionan como grupos intermediarios, captando la demanda o impulso del voluntariado, que surge masivamente en las sociedades desarrolladas, para lo cual crean la infraestructura indispensable, que pone a disposición del cliente previa aportación económica: hospedaje, transporte, información mínima sobre el lugar de destino, orientación y/o entrenamiento social; y los contactos necesarios para penetrar sin conflictos a las colonias populares, cárceles, penitenciarías, orfanatorios, etcétera. Estos grupos tienen un carácter de mediadores entre el voluntario y los pobres; disponen de personal especializado en la elaboración de paquetes de "turismo beneficencia", que buscan satisfacer la demanda de una clase ávida de proletarizarse temporalmente con la intensión de "curarse de sus pecados", o de llevar a la práxis las enseñanzas bíblicas de ayuda al necesitado, perdiéndose en una de tantas zonas marginales entre pobres de carne y hueso, o en un subdesarrollado orfanatorio repartir abrazos y caricias o alimentos a niños abandonados, que confusos por las visitas frecuentes indistintamente llaman a todos papá o mamá.

Responsability previa visita de sus voluntarios a Tijuana, les imparte conferencias sobre México con duración de un día. Los Niños también aleccionan a sus voluntarios de fin de semana; otros grupos realizan estudios antes de establecerse. En 1985 una SR fundamentalista elaboraba una investigación sobre el valle de San Quintín para ver la posibilidad de trabajar allí.

SOCIEDADES RELIGIOSAS Y ORGANIZACIONES PRIVADAS DE BENEFICENCIA,SU IMPACTO EN COLONIAS POPULARES (DOS CASOS)

\section{Colonia Leandro Valle}

La presencia de "los gringos" en su colonia, fundada hace 20 años se volvió un hecho común para Juana (una joven de 25 años). La llegada de extraños en el principio fue noticia ya que a ellos, a los pobres, a los 364 
habitantes de la Leandro Valle (para 1986) abandonados a su suerte y sin servicios públicos, finalmente alguien se interesaba por atenderlos, desde entonces cientos de toneladas de ropa, alimentos, medicinas les han sido donados, haciéndose costumbre esta práctica. Varios días a la semana llegan distintos grupos, y Juana es una de las primeras en formarse horas antes en la hilera de vecinos, donde personas de otras colonias, también hacen su peregrinar semanal para recibir los obsequios de los "gringos del norte". Los grupos visitantes tienen sus propios intereses en la esfera religiosa, la estrategia es el obsequio material como un primer incentivo, para después convencerlos de la "palabra del Señor". Cada sábado una de las sectas pentecostales envía camionetas a diferentes colonias, para traer gente a esta colonia reuniendo a más de trescientas personas quienes recibirán como siempre ropa usada y comida "chatarra". A los habitantes de la colonia Leandro Valle no les ha parecido que de otras colonias vengan a recibir lo que ellos inicialmente les corresponde "por derecho"; por lo que no es extraño que surjan problemas personales, reclamaciones e insultos. El lugar donde hacen los obsequios es casualmente frente al modesto templo pentecostal, construido con madera de segunda, con la intención de que al término de las donaciones se animen a entrar a los servicios religiosos. A un costado del templo han construido un dispensario al que orgullosamente llaman "la clínica", atendida semanalmente por doctores norteamericanos. A pesar de la estrategia, sólo acuden al llamado religioso de diez a quince personas, otras a consulta y el resto se retira satisfecho; incluso algunos molestos por lo poco que les tocó o lograron arrebatar en momentos en que el orden en la hilera se rompía y en forma desesperada se avalanzaban sobre sus beneficiarios, arrancando de sus manos los vestidos pasados de moda, zapatos usados, etcétera. Con el tiempo, las anteriores actitudes provocaron que las SR y OPB (que en conjunto sumaban tres) se ahuyentaran, ya que la llegada masiva de habitantes de otras colonias, los días en que los alimentos eran repartidos, significó conflictos entre éstos y los vecinos de la colonia Leandro Valle, y con los norteamericanos a quienes llegaron a reclamarles y exigirles más ayuda, ya que la que entregaban no era suficiente. Ahora estas organizaciones se dirigen a la colonia vecina, lo que lamentan en la Leandro Valle, culpando a los "instrusos" de las otras colonias.

La OPB Los Niños, de 1981 a 1985, visitó la colonia donando alimentos a la única escuela primaria del lugar, mantuvo un programa de nutrición, cursos de verano, inglés y trabajos manuales, contando siempre con el apoyo de un vecino de la comunidad quien proporciona "asesoría escolar". El siguiente fragmento del diario de un voluntario de Los Niños, quien permaneció casi un año en la colonia, describe la presencia de las SR y OPB: 
Cientos de mujeres y niños de todo Tijuana llegan y pelean por los lugares en la hilera, para recibir estos bienes que con frecuencia.... Otro grupo vino a construir viviendas [.... El hecho es que los grupos americanos, con su extrema riqueza, pueden proporcionar más dinero y bienes, hacer un viaje de campo, ir a lugares más exitantes, y hacer mejores cosas que las que la gente de la comunidad puede hacer por sí misma (Voluntario de Los Niños, Diario personal, 1985).

Haciendo un balance de las cosechas religiosas en esta colonia, el resultado no es muy alentador para las SR, son pocos los convencidos que han abandonado el catolicismo para hacerse "aleluyas" o "hermanos" como los llaman indistintamente:

No nos gusta la palabra de Dios, lo que nos gusta es lo que traen, $y$ lo que ha sucedido es que nos hemos acostumbrado. También vienen negros a dar cosas, pero no se de que grupo religioso son, pero no importa de que religión son, mientras sigan trayendo donas. Aquí nomás recibimos las cosas por conveniencia (Líder de la Colonia Leandro Valle, comunicación personal, 1985).

Así se expresa el líder de la colonia y miembro de la Coalición Municipal de Colonias Populares, afiliado a la Confederación Nacional de Organizaciones Populares (CNOP), y filial del Partido Revolucionario Institucional (PRI). No obstante, las SR no desmayan en su labor pastoral, son como gotas de agua, insistentes, seguras y llenas de fe; la tarea es difícil pero no imposible, y gracias a un metódico y paciente trabajo han logrado expandirse a otras colonias.

\section{Colonia Anexa Panamericana}

Ellos vinieron, nosotros no les dijimas que vinieran.

Esta colonia fundada a principios de los setenta está asentada sobre un antiguo ex basurero; para 1985 tenía cerca de 250 habitantes y no contaba con servicios públicos. La colonia Anexa Panamericana sintetiza casi todas las prácticas sociales descritas párrafos atrás.

Los fines de semana la colonia se convierte en una especie de anti Disneylandia ya que a manera de "tour" representantes de quince organizaciones religiosas y de beneficencia, se disputan la misma clientela recorriendo a pie, entre basura y desperdicios, visitando las casuchas y sus habitantes, saludando y saludándose, repartiendo comida, invitando a la lectura de la biblia, recordando su próxima visita y el cercano advenimiento de Cristo, pronunciando mal el español y cumpliendo con seriedad su papel 
de enviados o representantes del Señor, o de voluntarios dispuestos a todo. Los americanos se han apropiado finalmente de este reducido espacio fronterizo, convirtiéndolo en su propio enclave: "Esta colonia y el dompe (basurero) son las colonias de los mantenidos, porque vienen muchos 'hermanos' a traer cosas. Ellos vienen, nosotros no les dijimos que vinieran" (Líder de la colonia Anexa Panamericana, comunicación personal, 1985).

Una pareja de jóvenes estadounidenses fundaron el grupo Clínica Primavera, instalándose en un viejo autobús escolar que les ha servido de vivienda y centro de operaciones. Uno de sus proyectos consistió en financiar una cooperativa para la crianza de puercos, con fondos provenientes de una fundación americana, la inversión inicial fue de un millón de pesos, dinero canalizado a los líderes de la comunidad y dos de sus incondicionales, provocando la inconformidad de los vecinos, ya que estos líderes, verdaderos caciques de la colonia, astutamente han aprovechado toda "ayuda" de los americanos, para hacer de ella su modus vivendi, ayuda que en gran parte les es canalizada en su calidad de representantes de la colonia, lo que ha servido para reforzar su poder caciquil y mantener un férreo control sobre la comunidad.

Don Julián y su familia son otro ejemplo negativo del impacto de estas organizaciones. Hace ya muchos años que emigraron de Jalisco, y desde entonces se dedican a trabajar como pepenadores entre la basura y a vivir a un lado de ésta. Han sido testigos de la llegada constante de americanos; de la construcción de dos reducidos templos de madera, uno evangelista otro católico; de las "vans" del año y de los autos impecables todos con placas de California, Arizona, Washington y Nevada y otras que no recuerdan, que van y vienen constantemente atravesando los polvosos caminos de terracería que llevan a la colonia. Don Julián ha sido un hombre con suerte en los últimos años, gracias a "los gringos" y sobre todo a su habilidad para obtener de éstos todo, o casi todo: "Yo, ya no tengo por qué trabajar; un grupo construyó mi casa, otro nos trae doctores y medicinas; otro baña a mis niños; otro, nos trae ropa; otro comida; otro tiene becados a mis hijos, uno en California".

$\mathrm{Y}$ cuenta que unos "hermanos" les han asegurado, incluso un lugar en el paraíso. No todos los vecinos son tan afortunados como la familia de don Julián, quien ha dejado de trabajar ahora que le han "solucionado" sus necesidades familiares primordiales, para dedicarse a la bebida. Este es un ejemplo del impacto negativo en la estructura familiar.

La presencia masiva de estas organizaciones ha provocado conflictos entre los habitantes de la colonia, y vecinos de otras zonas que semanalmete acuden también a recibir donaciones. 
Las primeras consecuencias de la presencia de estos grupos no sólo se reflejan en la estructura familiar, en el reforzamiento de estructuras caciquiles o en los conflictos comunales; a nivel macro están supliendo funciones que corresponderían en primer término al Estado y a los sectores privilegiados económicamente, quienes se han desentendido de atender a los pobres. En este país si alguien tiene la obligación de proporcionar los mínimos de bienestar al pueblo es el Estado, sin embargo, grupos de extranjeros cumplen con estas funciones. La responsabilidad de proporcionar salud a través de instituciones oficiales aquí la asumen los americanos; la obligación de llevar alimentos al alcance del pueblo a través de mercados sobre ruedas, etcétera, es reemplazada por donaciones de alimentos "chatarra", en su mayoría; el deber del Estado de financiar la construcción de viviendas para las clases populares, se ve suplida por la construcción de casas por Amor Ministry; al Estado corresponde dar educación y programas de becas, no obstante, SR y OPB realizan esta labor, incluso becando a jóvenes en Estados Unidos, donde adoctrinados religiosamente son preparados para trabajar en sus propias comunidades; el agua que no llega a estas colonias, es suministrada por los mismos norteamericanos; un grupo obsequia semanalmente galones de plástico con agua potable y otro transporta agua tibia en tanques, para bañar a niños y "desinfectarlos",

En julio de 1986 se celebró en Sonora el Primer Encuentro Regional de Organizaciones Populares del Noroeste, organizado por el Centro de Apoyo a Movimientos Sociales Urbanos (CAMSU), y el Grupo Regional de Apoyo al Movimiento Popular del Noroeste (GRAMPO). Entre las veinte organizaciones populares participantes, se encontraba la pareja de norteamericanos de Clínica Primavera, quienes venían como "delegados de la colonia Anexa Panamericana". En ningún momento los habitantes de la colonia les dieron tal representación, y tampoco se enteraron de que habían sido representados en la reunión. Este ejemplo muestra a este grupo extranjero como mediador ante organizaciones populares, sin contar con autorización de los interesados, hablando a su nombre y tomando decisiones que sólo corresponderían a los vecinos de la colonia.

Se da también un cambio de percepción de la población, en cuanto al compromiso del Estado y su responsabilidad social con las mayorías:

Los pobres observan cómo algunas o casi todas sus necesidades básicas, van siendo resueltas no precisamente por mexicanos, sino por extranjeros con el consentimiento del Estado. Esta situación no es desconocida por este último, quien hace uso de sus mecanismos de control político y social en las colonias populares, por una parte, a través de 
representantes de la Confederación Nacional de Organizaciones Populares (CNOP) filial del Partido Revolucionario Institucional (PRI) y por otra, por medio de líderes prí́stas. Ambos avalan la presencia de los grupos en la colonia Anexa Panamericana conociendo su impacto, aunque no en detalle, a la vez que se han convertido en beneficiarios, ya que las SR y OPB le restan responsabilidades al Estado, al subsidiar colonias populares, creando una relación asistencialista y dependiente que propicia el reforzamiento de actitudes autoritarias y de dominación de líderes corruptos, y crea un inmovilismo social que finalmente favorece a las clases dominantes.

Los miembros de la comunidad establecen estrategias con la intención de presentar una imagen de mayor pobreza de lo que en realidad son, y así obtener mayores beneficios. A lo largo del trabajo de campo encontramos una serie de actitudes para engañar al visitante, y obtener de éste bienes, dinero, etcétera; los ejemplos van desde narrarles historias dramáticas, ficticias o verdaderas de algún incidente familiar, hasta la aparente urgencia de dinero. Uno de los entrevistados relata que cuando los visitan "los negros", refiriéndose a norteamericanos de color de Tree Vine Baptist Church: "Fingen tener el don de lenguas tirándose al suelo mientras otros gritan y otros le hacen al cuento, diciendo que tienen al diablo dentro y se revuelcan, ya que los negros nos dan 10 dólares".

Conociendo los días en que llegan los miembros de los OPB y las SR, también conocidos como "hermanos" o "aleluyas", los habitantes de las colonias se visten con ropas más humildes para dar la impresión de extrema pobreza y compasión a los ojos de sus "benefactores", de quienes obtendrán más ayuda, dado que esta táctica ya ha sido utilizada con buenos resultados en ocasiones anteriores. La mayoría de las madres que hacen fila para que sus hijos sean bañados y "desinfectados", confiesa no haberlos aseado en toda la semana intensionalmente, con el propósito de crear una imagen de mayor pobreza.

En el campo religioso, a pesar de la presencia masiva de estas organizaciones, en el sustrato la mayoría continúa siendo católica, e incluso en algunos casos engañando a los norteamericanos al asistir a sus templos, con el único propósito de obtener beneficios. Encontramos individuos en una etapa religiosa transitoria, en su intimidad encendían velas a la virgen María, mientras acudian al templo pentecostal según expresaron "porque nos gusta el ambiente", "nos tratan bien", "simpre regalan cosas" o "son muy buenos".

El cuadro 1 muestra el número de grupos en varias colonias, cuyo número de voluntarios aumenta en las vacaciones de verano. 
CUADRO 1. Intensidad y número de organizaciones religiosas y de beneficencia

Anexa Panamericana

$\begin{array}{lc}\text { alta } & 15 \\ \text { alta } & 10^{*} \\ \text { alta } & 10^{*} \\ \text { media } & 3 \\ \text { baja } & 2\end{array}$

FUENTE: Observación directa del autor NOTA: * Cifras aproximadas.

Otras consecuencias de la presencia de sociedades religiosas y de beneficencia en colonias populares

La relación SR/OPB-comunidad involucra una interacción en dos direcciones: centros metropolitanos-comunidades subdesarrolladas. La naturaleza de los contactos comprende a sociedades que difieren en su grupo de productividad y poder. A partir de esta relación se da la introducción e imposición de una nueva realidad socioeconómica y político religiosa, frente a la cual la comunidad opone una pasiva resistencia adaptándose para obtener el máximo de beneficios de estos grupos.

En la metrópoli el efecto inmediato derivado de la exportación de expresiones religiosas y formas asistencialistas, es la creación de una infraestructura que les asegure apoyo económico y la habilidad para obtenerlo. Tan sólo "Los Niños" mantenía en 1985 un presupuesto anual de aproximadamente 70 mil dólares; Jimmy Swaggart (Asamblea de Dios), había abierto, hasta 1986, misiones y oficinas de caridad en 53 países (Times, 17 de febrero de 1986).

La duración del encuentro SR/OPB-comunidad puede ser de horas, semanas o prolongarse por años; lo mismo que variar en su intensidad. Con el tiempo estos grupos van estableciendo relaciones personales con miembros claves de la comunidad:

Miguel [líder] es el de los terrenos, el que habla con los americanos, el que manda aquí, también es el dueño de la coNASUPO [tienda]; es el único que habla inglés; y con Juana y Eusebio llegan 
Ios americanos a darles comida y ellos la reparten a quienes quieren (doña Emilia, residente de la colonia Anexa Panamericana, comunicación personal).

A diferencia de las áreas turísticas en donde la realidad es maquillada para ofrecer una imagen distorcionada al visitante, en las comunidades estudiadas su realidad no era alterada para presentar la mejor cara, sino se acentuaba su pobreza con el fin de obtener mayores utilidades.

Venían muchos grupos religiosos, entonces viviamos en el basurero, pero nomás vieron que mejoramos y dejaron de venir. $\mathrm{Me}$ acuerdo que venían muchos grupos de norteamericanos, muchos, incluso negros, casi todos aleluyas (líder de una colonia vecina a la Anexa Panamericana, comunicación personal).

Si graficamos el modelo de beneficencia de las SR y OPB tendríamos una figura en forma de pirámide (marcada con línea continua) donde se representan, de arriba hacia abajo, los grados de pobreza clasificados arbitrariamente; y un triangulo invertido (marcada con línea punteada) que significaría de arriba hacia abajo, el número de SR y OPB, a mayor pobreza más organizaciones y viceversa (ver figura 1).

El norteamericano aparece ante los ojos de la comunidad (aun sin proponerselo) como un ser superior, por su riqueza; como el salvador y dador de bienes provenientes de una sociedad altamente industrializada que reafirma así su superioridad y dominio sobre los países subdesarrollados. El visitado es percibido como un individuo en extremo pobre, ingenuo, dócil y condescendiente, esto provoca en ellos sentimientos de inferioridad que tienden a desaparecer en la medida en que advierten las debilidades de su benefactor, $y$ establecen estrategias para utilizarlos en beneficio propio.

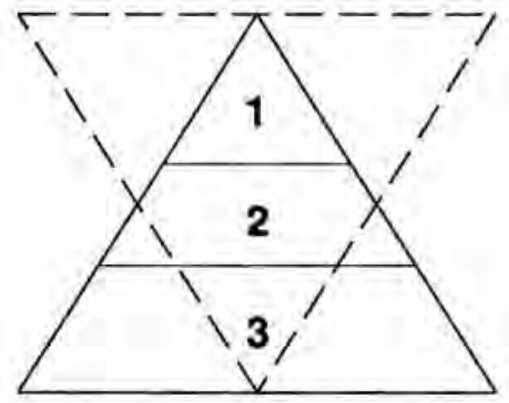

1. Alta pobreza

2. Media pobreza

3. Baja pobreza

\section{FIGURA 1}

FUENTE: Elaborado por el autor. 
La imagen de riqueza del visitante es reforzada por la práctica de la beneficencia. Esta práctica social fortalece el estereotipo que considera a todo extranjero proveniente del norte como rico. El mismo "beneficiario" no comprende cuál es la razón, fuera de los intereses religiosos y asistencialistas, de las visitas y donaciones insistentes.

Una mujer de la colonia Leandro Valle, al preguntarle cual creía era el motivo por lo que venían los americanos, contestó: "Todos esos, no te creas que vienen a ayudar por que quieren, las fotos que nos toman, las presentan en los Estados Unidos y obtienen dinero".

En esta asimétrica relación existen casos de desconocimiento mutuo, en el que poco o nada saben uno del otro: "Los que hacen casas no los conocemos, como no hablan español vienen y se van" (Mujer residente de la colonia Anexa Panamericana, comunicación personal, 1986).

La comunidad tiene la posibilidad de observar permanentemente a los norteamericanos, ya que repetitivamente los visita el mismo tipo de norteamericano trátese de un voluntario o un religioso.En cambio, las condiciones son distintas para los grupos que realizan visitas temporales ya que les falta tiempo para conocer mejor a la comunidad; incluso, de los americanos radicados en las colonias estudiadas eran pocos los que tenían una visión objetiva de las condiciones sociales, políticas, económicas y culturales de la frontera y el país. En términos generales prevalecía una imagen anticuada y distorcionada, además de enfrentamientos entre las organizaciones por la clientela. Algunos grupos proporcionaban información veraz sobre la frontera; otros como el Lutheran Border Concerns Ministry en una cuartilla daban una visión global equivocada del país y la frontera, iniciando su información con el siguiente encabezado: "Tijuana ¡Una ciudad que esperó ser! La ciudad de Tijuana, extendida sobre cerros en la frontera México-Estados Unidos, a quince millas al sur de San Diego, es en realidad una nociudad. No existe una razón lógica para su existencia".

\section{CONCLUSIONES}

La frontera norte es ahora escenario de una intensa actividad proselitista, que ha propiciado que el campo religioso se vuelva más competitivo. No obstante, a diferencia del sur del país, es una sociedad más tolerante en cuanto a aceptar otras sociedades religiosas no católicas. El amplio expectro religioso ha pasado a formar parte de la cultura fronteriza.

Como resultado de la presencia de nuevas expresiones religiosas, el clero católico puede verse presionado a adoptar actitudes más progresistas, novedosas o conservadoras (estas últimas parecen dominar ante las sectas) 
que en otras circunstancias nunca se darían; o en caso contrario, reforzar su actitud original, llevando sus planteamientos a una simple competencia por conservar el espacio religioso ya ganado.

El fenómeno migratorio ha servido a la expansión de las organizaciones religiosas, al poner a su disposición un ejército de reserva permanente que se nutre principalmente de miles de migrantes, potencialmente susceptibles de ser convertidos. Por lo que no sorprende encontrar que las sociedades religiosas que más rapidamente crecen en México y la frontera sean las mismas que dedican mayor atención a los hispanos en California.

El valle de San Quintín, en cuanto al impacto de las organizaciones religiosas, adquiere una dimensión distinta a los centros urbanos de Baja California por su alta población de indígenas migrantes; indígenas que han ido estructurando enclaves culturales hacia el interior, de los cuales reproducen patrones rurales como una forma de defensa frente a un medio social que les es agresivo (Clark, 1990).

La introducción de expresiones religiosas no católicas en pueblos indígenas del sur del país, ha trastocado la estructura política-cívicoreligiosa con la consecuente división, provocando en ocasiones enfrentamientos violentos de quienes ven su presencia como un intruso en su comunidad; por lo que no sería sorprendente que esto también sucediera en San Quintín.

Creemos que la forma en que el Estado y el clero católico tratan de enfrentar el "problema" de los testigos de Jehová, no es la más adecuada. La actitud del Estado es atentatoria a los derechos humanos, a la vez que ha resultado contraproducente provocando sólo que los testigos refuerzen sus personales interpretaciones bíblicas como un "pueblo perseguido", e impulsándolos a buscar otros mecanismos para resolver su problema educativo. Las constantes referencias negativas del clero católico sobre los testigos de Jehová, sólo ha encontrado de parte de éstos el silencio como respuesta; por lo que creemos que estas conductas deben referirse.

Las organizaciones privadas de beneficencia junto con las sociedades religiosas, son uno más de los elementos aculturantes provenientes del norte. La presencia de numerosas OPB parece ser, por su cercanía con Estados Unidos, más un fenómeno fronterizo ya que en el centro y sur del país su número es reducido,

Los impulsos del voluntariado hay que rastrearlos en las sociedades desarrolladas, donde existe un excedente de tiempo libre, recursos económicos, espíritu de aventura y motivación religiosa. En el heterogéneo grupo de voluntarios se da un proceso de desclasamiento, en lo que Bartra llamaría "la proletarización de la burguesia", o más especificamente "la proletarización del dominador" (Bartra, 1981). 
Los "lour de la pobreza" que muchos de estos grupos organizan, se han convertido en un importante negocio en los dominios de la filantropía. Su actividad ha ido creando una economia de la caridad, cuyas donaciones económicas y materiales, si bien responden a necesidades básicas de la comunidad lo que sería una consecuencia positiva, estan al mismo tiempo creando relaciones asistencialistas que se inscriben a otro nivel en las relaciones económicas internacionales de dependencia: "Más bienes y servicios son transmitidos por agencias privadas americanas a países en desarrollo, que la asistencia que es enviada a través de la ayuda oficial norteamericana para el desarrollo" (Forsy, 1989).

A este nivel las OPB han asumido, también, la responsabilidad de implementar una política exterior norteamericana de la beneficencia sin supervisión congregacional o pública.

Algunos grupos se han percatado del daño que sus acciones causan, tratando de reorientarlas promoviendo la autosuficiencia comunitaria; lo cierto es que no es suficiente esta reorientación, mientras sean otros los que decidan por la comunidad e impongan elementos ideológicos y simbólicos, como parte del modelo hegemónico del grupo dominante.

\section{BIBLIOGRAFÍA}

BACKHOFF, Eduardo E. 1987. "Templos y grupos religiosos en Ensenada, B. C.: un estudio cuantitativo" (mimeo).

BARTRA, Roger. 1981. Las redes imaginarias del poder político, ediciones ERA, México.

CLARK Alfaro, Víctor. 1986a. "Grupos religiosos en la frontera norte (Tijuana), un primeracercamiento", Inventario, no. 28, 11 de mayo.

- 1986a. "Medios masivos de comunicación", Inventario, no. 30, 18 de mayo,

- 1986b. "Beneficiencia y asistencialismo", Inventario, no. 46, 14 de septiembre.

- 1986c. "Algunas consecuencias de la presencia de los grupos religiosos y grupos de beneficencia", Inventario, no. 57, 30 de noviembre.

- 1987. "Derechos humanos de los migrantes mixtecos: Baja California-California", Centro Binacional de Derechos Humanos, ponencia presentada en la reunión anual de la Society for Applied Anthropology, Oaxaca, Oax. 8 al 12 de abril.

- 1988a "Organizaciones de los mixtecos migrantes en el norte de México y Estados Unidos", Seminario Permanente de Estudios 
Chicanos y de Fronteras-INAH, ponencia presentada en el Foro Internacional de Migraciones Mixtecas Hacia la Frontera Norte de México y Estados Unidos, Tijuana, Los Ángeles, Distrito Federal y Oaxaca. Mayo.

- 1988b. "Medios masivos de comunicación religiosos en la frontera (Tijuana)", (mimeo).

- 1990. "Los mixtecos en la frontera". Cuadernos de Ciencias Sociales. Serie 4, no. 10. Universidad Autónoma de Baja California. COLEGIO DE ETNÓLOGOS Y ANTROPÓLOGOS SOCIALES, A. C., El ILV en México, México.

COMISIÓN EPISCOPAL ALTA/BAJA CALIFORNIA. 1990. "Exhortación pastoral sobre el proselitismo". Tijuana B. C., 28 de febrero.

FORSY, David P. 1989. Human Rights World Politics. University of Nebraska Press, Lincoln, Londres.

FREIRE, Paulo, 1983. Pedagogia del oprimido, siglo XXI editores, 30a. edición, México.

GIMÉNEZ, Gilberto. 1988. Sectas religiosas en el suroeste, aspectos sociológicos y estadísticos. Centro de investigaciones y estudios superiores de antropología social, CIESAS del suroeste, Cuadernos de la Casa Chata 161, México, D. F.

HERNÁNDEZ, Alberto. 1989, "Resultados de la investigación sobre grupos religiosos", Colegio de la Frontera Norte, octubre.

HUDSON, Winthrop S. 1973. Religion in America, Charles Scribner's Sons, New York.

JOHNSTONE, Ronald L., 1975. Religion and Society in Interaction, the Sociology of Religion, Prentice-Hall, Inc. Englewood Cliffs, N. J.

LEBARON, Verlan M. The LeBaron Story, Keels \& Co. Inc. Lubbock, Texas.

MANN, Brenda J, 1972, "The great croud: ethnography of Jehovah's witnesses", en: James P. Spradley y David W. McCurdy, The Cultural Experience Ethnography in Complex Society, Science Research Associetes, Inc. Chicago.

O'DEA, Thomas F. 1978. Sociologia de la religión. Ed. Trillas. México. POPE, Liston. 1942. Millhands and Preachers. New Haven, Yale University Press.

READ, William R., Víctor M. Monterroso y Harmon A. Johonson, 1969. Latin America Church Frowth, William B. E. Ermands Publishing Company, Michigan.

SPP-INEGI, 1980. Censo general de población y vivienda 1980.

STARK, Rodney y William Sims Baimbridge. 1985. The Future of Religion, University of California Press. 
VALDERREY, José. 1985. Las sectas en Centroamérica. Pro Mundi Vita. Bruselas.

WATCH TOWER BIBLIE AND TRACT SOCIETY OF NEW YORK, Inc. 1985. Libro de textos bíblicos para 1983. Broling, N. Y. EUA. WHALEN, William J. 1979. Separated Brethren, Our Sunday Visitor, Inc. Hungtington, Indiana. 